\title{
Policy Performance Analysis of Six Stability and Six Guarantees Based on Empirical Analysis
}

\author{
Yuchen $\mathrm{Liu}^{1, \mathrm{a},{ }^{*}, \dagger}$, Yunyi $\mathrm{Qi}^{2, \mathrm{~b},{ }^{*}, \dagger}$ \\ ${ }^{I}$ The School of finance, Henan Finance University, Zhengzhou, Henan, China \\ ${ }^{2}$ Faculty of Business, Economics \& Law, The University of Queensland, Brisbane, Australia \\ *Corresponding author. Email: ${ }^{a} 2682068462 @ q q . c o m,{ }^{b}$ yunyi.qi@uqconnect.edu.au \\ These authors contributed equally.
}

\begin{abstract}
In recent years, China's international situation is tense and will be affected by the Novel coronavirus in 2020. In this context, the government has put forward a policy of six stability and six protection, that should ensure the stability of employment, finance. At the same time should also implement the tasks of "six guarantees". "Six Stable" and "Six Guaranty" are important decisions for China to expand domestic demand and maintain domestic economic and social stability. This paper studies the performance analysis of the six stability and six protection policies on GDP policy. Taking Shandong province as an example, this paper analyzes the achievements of Shandong Province under the sixstability and six-guarantee policy Shandong province economic development quality and efficiency continued to improve. The relationship between economy, employment, and investment is complementary and mutually promotes development. AtDespite these pressures, China's economy has achieved good results. Its economic performance has improved quarter by quarter and gradually returned to normal. Its GDP grew by $2.3 \%$ year on year,that exceeded expectations and achieved major targets. The 13th Five-Year Plan drew to a successful conclusion, laying a solid foundation for the beginning of the 14th Five-Year Plan.China's six-stable and six-guarantee policy has played an irreplaceable role in stabilizing the social economy during the period of China's recovery from the epidemic by stabilizing employment and investment. Not only during the epidemic, but in the future, updating and supplementing the content of the policy based on real-time changes, it is also conducive to the better development of China's economy. The limitation is also discussed in the following paper.
\end{abstract}

Keywords: China's post-epidemic period; China's Six Stability and Six Guarantees Policy; Empirical analysis; Shan Dong; macroeconomi

\section{INTRODUCTION}

In order to cope with the changes in the international economic environment, especially the short-term hedging of the impact of the epidemic while optimizing the development structure and perfecting the long-term consideration of the development model. The work report of the Chinese government pointed out that by keeping the bottom line of the "six guarantees", the basic economic situation can be stabilized; by stability and seeking progress while maintaining stability,it can lay a solid foundation for building a well-off society in an allround way. China is the world's largest developing country. Despite the great negative impact of the COVID-19 in recent years, China can still stabilize the economy and achieve positive GDP growth. This is very much in line with the specific policies formulated by
China in a specific period. This report studies the economy and related policies after the epidemic in China, which is of great significance to the development of the world economy.

The year 2020 will be a very unusual year in China's history. Facing the impact of the epidemic and the tense international situation, the world economy is depressed and uncontrollable factors are increasing. In order to ensure the steady progress of China's domestic development and reform tasks, the central government timely put forward the new policy of "six stability" and "six guarantees". China should ensure the stability of employment, finance, foreign trade, foreign investment, investment, and expectations. At the same time, China should also implement the tasks of "six guarantees". China will ensure the employment of residents, the 
people's basic livelihood, market entities, food and energy security, the stability of the industrial and supply chains, and grass-roots operations. "Six Stable" and "Six Guaranty" are important decisions for China to expand domestic demand and maintain domestic economic and social stability. They also have a profound impact on China's economic situation and development level as well as changes in consumer goods and price levels related to residents' lives.

The COVID-19 has brought unprecedented difficulties and challenges to countries around the world. For this reason, the Chinese central government has put forward the slogan of solidly doing the "six stability" work and fully implementing the "six guarantees" task. In July 2018, the Central Economic Work Conference put forward the "six stability" policy for the first time. On September 4, 2019, Premier Li Keqiang of the State Council presided over an executive meeting of the State Council to deploy precise measures to intensify efforts to do the "six stability" work, determine measures to speed up the issuance and use of local government special bonds to drive effective investment support to supplement shortcomings and expand domestic demand. On April 17, 2020, the Political Bureau of the CPC Central Committee held a meeting to analyze and study the current economic situation and deploy current economic work. The meeting emphasized for the first time that the work of ensuring employment, ensuring basic people's livelihood, ensuring market players, ensuring food and energy security, ensuring the stability of the supply chain of the industrial chain, and ensuring the operation of the grassroots level is inseparable from the judgment of the current situation. In August 2020, the "Opinions of the General Office of the State Council on Further Doing a Good Job in Stabilizing Foreign Trade and Foreign Investment" issued by the General Office of the State Council in August 2020 put forward 15 policy measures to stabilize foreign trade and foreign investment. Which it will help stabilize foreign trade entities and stabilize the supply chain of the industrial chain.

The "six stability" refers to stabilizing employment, stabilizing finance, stabilizing foreign trade, stabilizing foreign investment, stabilizing investment, and stabilizing expectations, covering the main aspects of China's current economic life. This shows that the central government still shows confidence in achieving overall stability in the face of increasingly challenging domestic and international economic situations. This confidence comes from sound economic fundamentals and is also supported by effective methods of precise policy implementation. The "six guarantees" refer to ensuring the employment of residents, the basic people's livelihood, the main body of the market, the security of food and energy, the stability of the supply chain of the industrial chain, and the operation of the grassroots level. Also, doing a solid job of "six stability" and fully implementing the task of "six guarantees" are related to the overall situation of economic development and social stability. If people's livelihood is stable, people's hearts will be stable, and society will be stable.

Pang and Ma studied whether the "Six Stability and Six Guarantees" have an understanding of establishing the public value of universities [1]. Pei discussed the internal relationship between the "six stability", "six guarantees," and high-quality development [2]. Gu studied the path for private enterprises to focus on "six guarantees and six stability" to promote high-quality development [3]. Zhong and Wang thought about the "six stability" and "six guarantees" innovative, inclusive finance [4]. Judging from previous research, there are very few concretely related to the impact of the Six Stability and Six Guarantees policy on China's GDP, so this paper proposes such a research theme for discussion. This paper will conduct research from the literature review overview of economic effects on employment and investment, China's GDP data analysis in 2020, and specific examples of Shandong, China's implementation of the Six Stability, and Six Guarantees. Finally, the article will put forward prospects and recommendations for China's economic development in 2021.

\section{LITERATURE REVIEW}

This paper talked about the policy of ensure six priorities and six stabilities in six areas is largely based upon empirical studies that investigate how economic development affects employment and investment. Zhang Summarized the impact of the policy of "six stability and six guarantees" policy on China in 2020, and predicting in 2021[5]. Then, it puts forward suggestions and prospects on how to do a solid job in the "six stable" work in 2021, fully implement the "six secure" tasks, and ensure a good start of the "14th Five-Year Plan". On the basis of his research, this paper mainly studies the impact of the policy of six stability and six guarantees on employment and investment [5].

\subsection{The background of the six steady six guarantee policy}

In July 2018, China's external environment underwent significant changes. There were changes in China's economic performance while maintaining stability, and there were concerns about stability. The central government reviewed the situation, took precautions, and put forward the "six stability" as the basic requirement to realize the seek improvement in the stability of the Chinese economy. Thanks to the "Six Steady Measures", China's economy has withstood the impact of changes in the external environment and maintained steady and sound growth. In December 2019, the global COVID-19 epidemic had a huge impact on China's economy. Under the pressure of the epidemic, 
production, consumption, investment, import, and export were all seriously affected. Due to the epidemic, People were isolated at home, enterprises stopped work due to the epidemic, the market stalled, and the exchange rate fluctuated. The income of enterprises and residents declined or even went bankrupt, leading to losses for financial institutions and the government. The financial environment was extremely unstable. In addition, China is facing the deterioration of the external economic situation. In the first quarter China's import and export showed negative growth,Doing resulting in internal and external economic imbalance. Therefore, the central government in this crisis timely on the basis of "six stability", put forward the "six security" new goal, "six stability" and "six security" policy has played an irreplaceable role in stabilizing the social economy.

\subsection{Performance analysis of the six stable six Guarantee policy in 2020}

In 2020, in the face of the huge impact of the COVID-19 epidemic and the complex and severe environment at home and abroad, especially the severe impact of the COVID-19 epidemic, China's economic performance has recovered steadily and better than expected, development goals and tasks have been fully accomplished, the 13th Five-Year Plan has been successfully concluded, and the victory of building a moderately prosperous society in all respects is within sight.

According to the data released by the National Bureau of statistics, the annual GDP in 2020 was 1015986 billion yuan, an increase of $2.3 \%$ over the previous year at comparable prices[6]. In terms of quarters, it decreased by $6.8 \%$ year-on-year in the first quarter, increased by $3.2 \%$ in the second quarter, increased by $4.9 \%$ in the third quarter and increased by $6.5 \%$ in the fourth quarter[6]. By industry, the added value of the primary industry was 7775.4 billion yuan, an increase of $3.0 \%$ over the previous year; The added value of the secondary industry was 38425.5 billion yuan, an increase of $2.6 \%$; The added value of the tertiary industry was 55397.7 billion yuan, an increase of 2.1\%[6]. The per capita income of residents has doubled over that of 2010[6]. In terms of per capita disposable income, the per capita disposable income of residents in China will be 32189 yuan in 2020, with an actual increase of $2.1 \%$ after deducting price factors [6]. The growth of residents' income is basically synchronized with economic growth. The goal of doubling the per capita income of urban and rural residents in 2010 was achieved as scheduled [6].

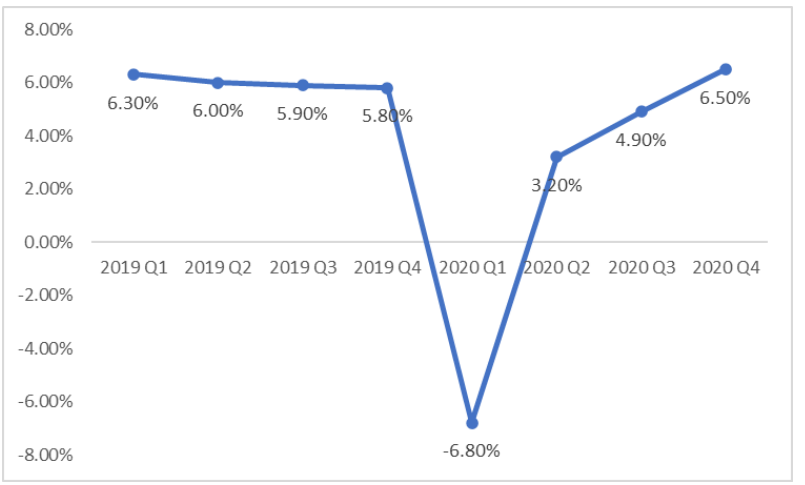

Figure 1 GDP Growth Rate (QY)

From January to December in 2020, the national fixed asset investment (excluding rural households) reached 5 [6]. 18907 trillion yuan, an increase of $2.9 \%$ over the previous year, and the growth rate was 0.3 percentage points higher that of January to November [6].

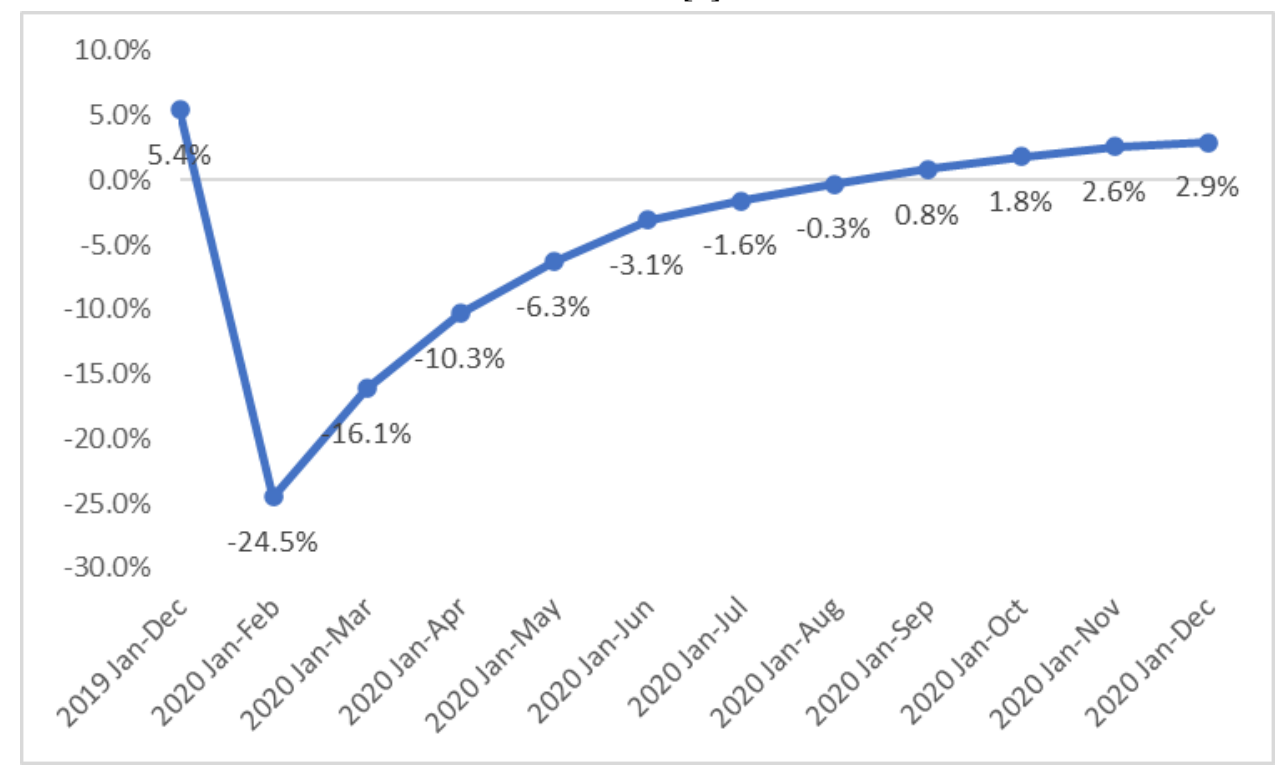

Figure 2 Fixed asset investment (excluding rural households) increased year on year

Grain production reached a new high, and pig production continued to recover rapidly. The total grain 
output in China was 669.49 million tons, an increase of $0.9 \%$ over the previous year, an increase of 5.65 million

tons [6].

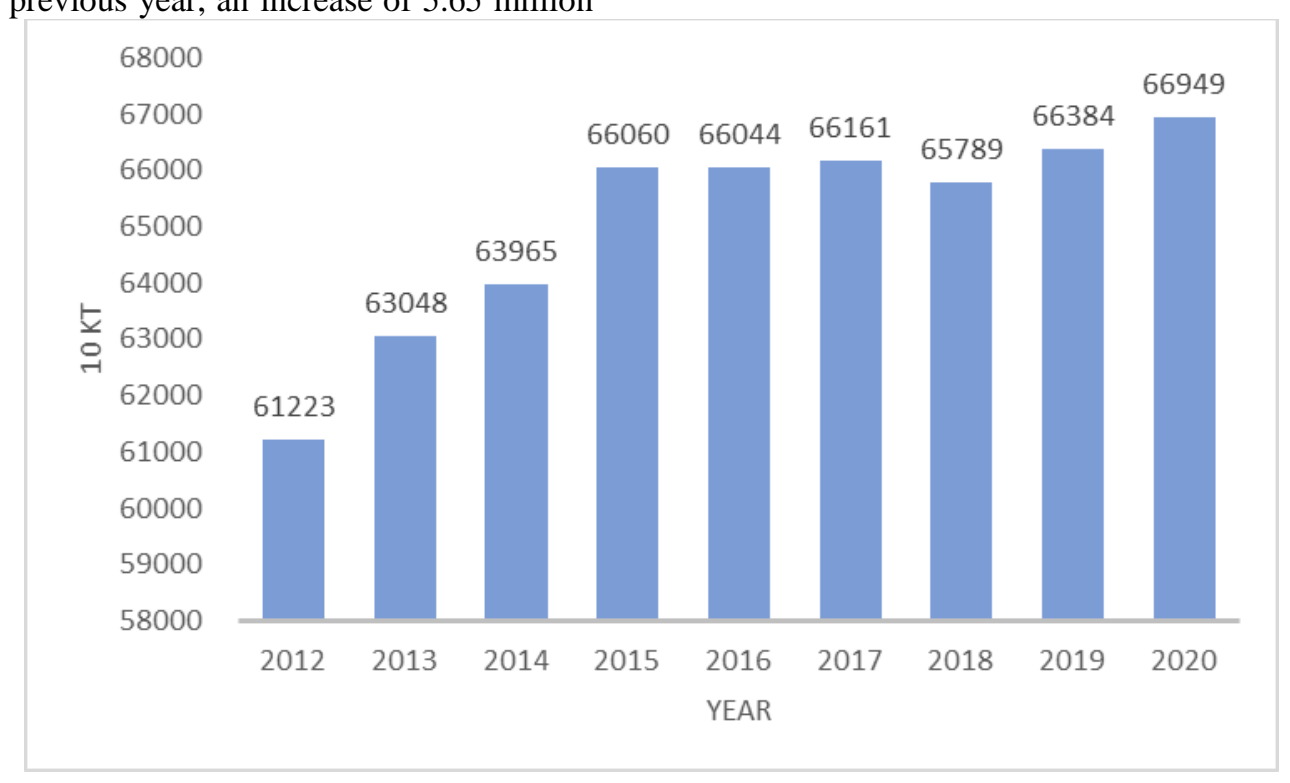

Figure 3 National grain output

Industrial production continued to develop, and hightech manufacturing and equipment manufacturing grew rapidly. The added value of national industrial above designated size increased by $2.8 \%$ compared with the previous year [6].

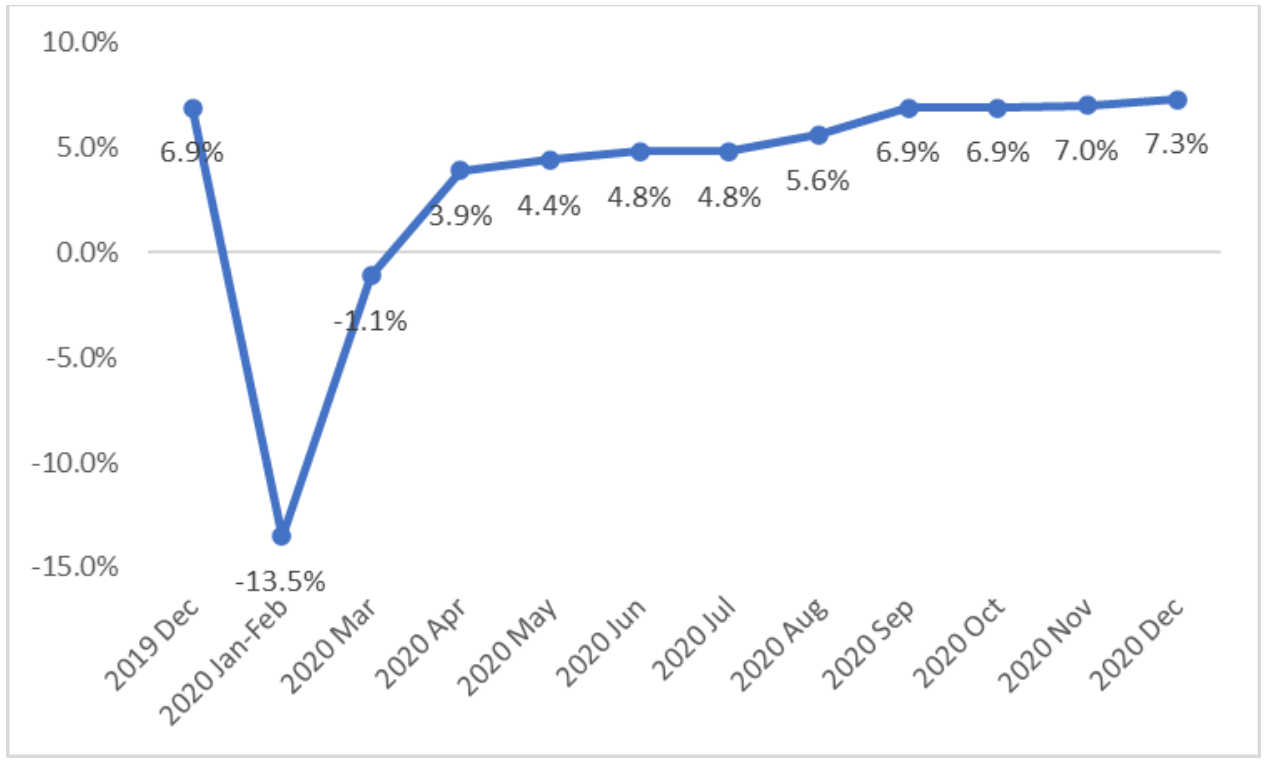

Figure 4 Growth rate of Industrial Added Value above designated size (monthly year-on-year)

The service industry is gradually recovering, and the modern service industry is growing well. The national service industry production index was flat with the previous year. Market sales recovered fairly quickly, and sales of consumer upgrading products grew faster. The total retail sales of consumer goods in the whole year reached 3.981 trillion yuan, down $3.9 \%$ compared with the previous year [7]. 


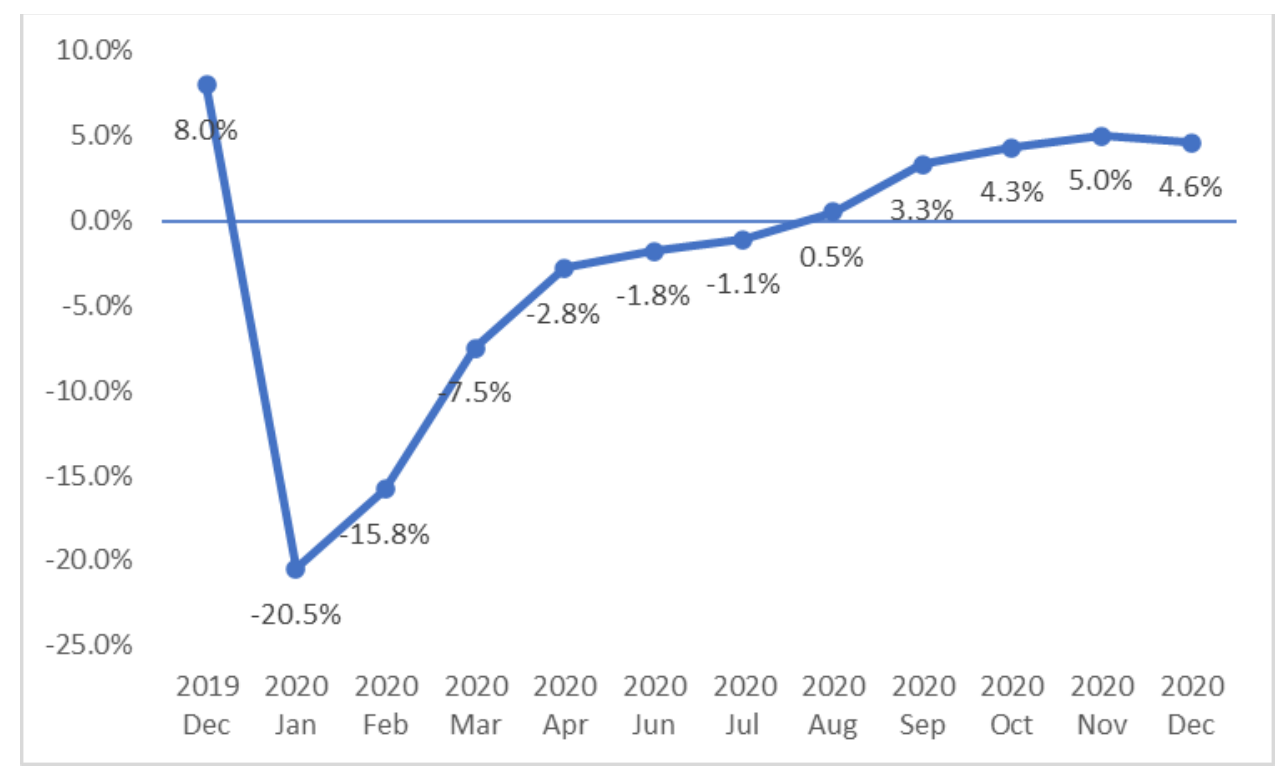

Figure 5 Growth rate of total retail Sales of Consumer Goods (month-on-month)

Investment in fixed assets rebounded steadily, and investment in high-tech industries and social sectors grew rapidly. In the whole year, the national fixed assets investment (excluding rural households) reached 5.18907 trillion yuan, an increase of $2.9 \%$ over the previous year [7].

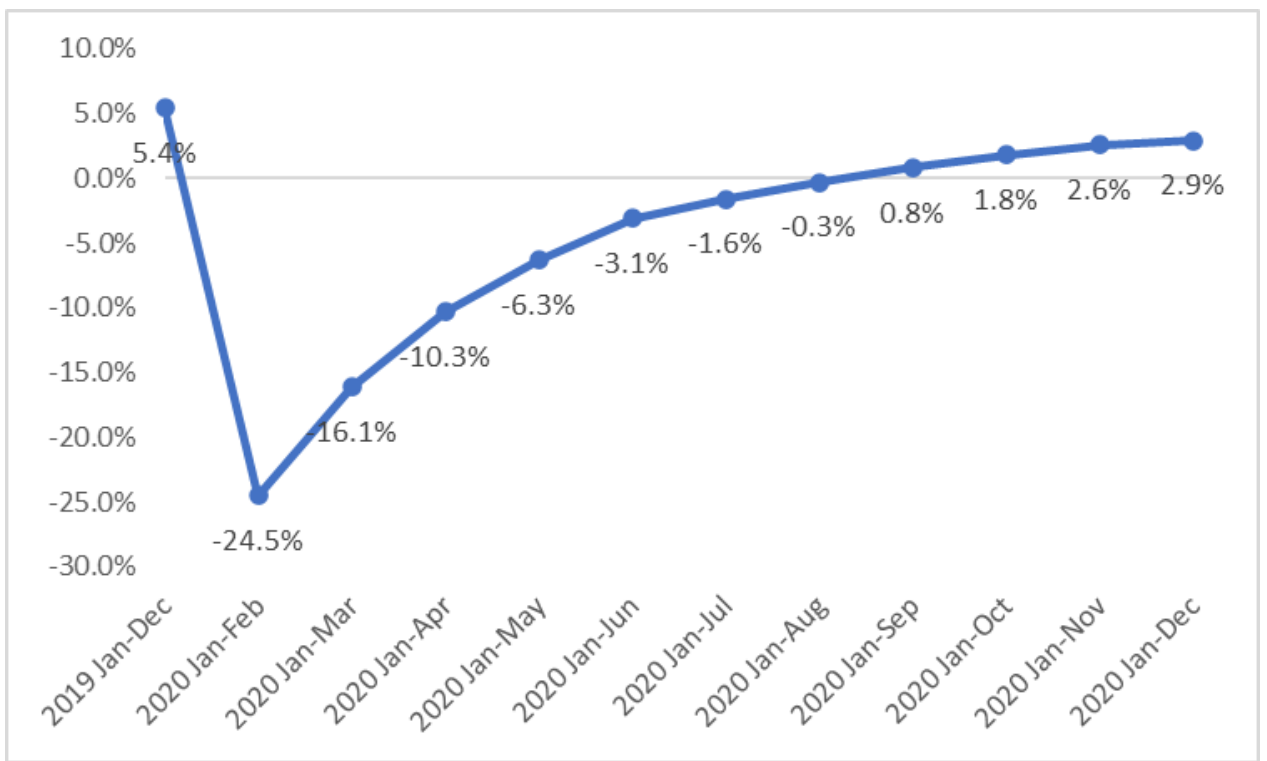

Figure 6 Growth rate of fixed asset investment (excluding rural households) (cumulative year on year)

Foreign trade achieved positive growth, and the trade structure continued to improve. The total import and export of goods in the whole year was 3.21557 trillion yuan, up by $1.9 \%$ over the previous year [7].

The rise in consumer prices fell, and producer prices fell. The consumer price index (CPI) rose 2.5 percent for the year, down from 2.9 percent in the previous year and below the annual target of around 3.5 percent[8]. Among them, the urban growth rate is $2.3 \%$, and the rural growth rate is $3.0 \%$ [8]. 


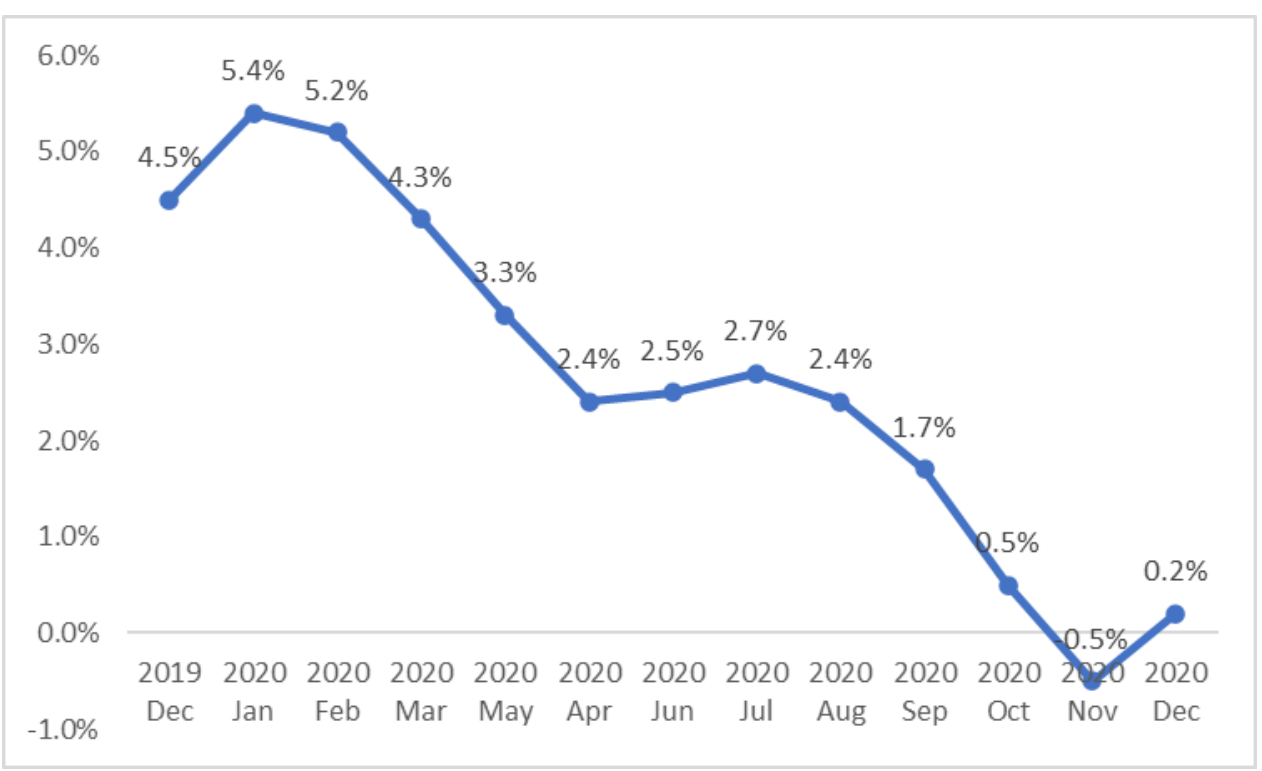

Figure 7 Consumer Price Increase (month-on-month)

The overall employment situation remained stable, and the surveyed urban unemployment rate fell back to the level of last year. 11.86 million new urban jobs were created. During the year, significantly higher than the expected target of more than 9 million, and $131.8 \%$ of the annual target was achieved [8].

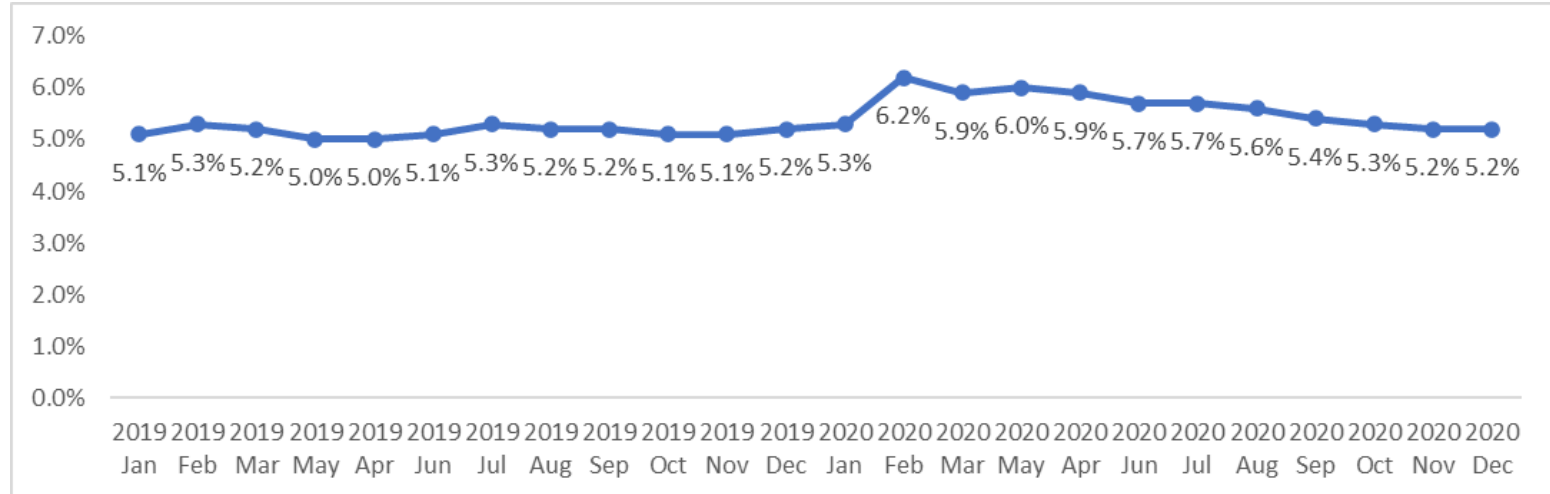

Figure 8 Surveyed urban unemployment rate

New progress will be made in stabilizing employment in 2020. In 2020, 11.86 million new urban jobs will be created, significantly higher than the projected target of 9 million and $131.8 \%$ of the annual target; New growth was achieved in the financial sector [5]. In 2020, the bond market issued a significant increase, with a total of 57.3 trillion yuan of bonds issued, an increase of $26.5 \%$ over the previous year; And making steady progress in foreign trade [5]. In 2020, China's total value of imports and exports in goods reached US \$4.64626 trillion, up $1.5 \%$ year on year, and China will remain the world's largest trader in goods. In 2020 , the actual use of foreign investment will reach nearly 1 trillion yuan, an increase of $6.2 \%$ year on year, achieving "three improvements" in the total amount of foreign investment, the growth range and the global share of foreign investment. Investment in fixed assets (excluding rural households) will reach 51.9 trillion yuan in 2020, an increase of 2.9 percent over the previous year [5]. Among them, infrastructure investment increased by $0.9 \%$, manufacturing investment by $-2.2 \%$, and real estate development investment by $7.0 \%$; Preliminary estimates show that China's GDP in 2020 will reach 101.6 trillion yuan, or about 14.7 trillion U.S. dollars [5]. China's GDP will exceed 100 trillion yuan for the first time, making China the only major economy in the world to achieve positive economic growth [5].

\subsection{Taking Shandong Province as an example}

To strengthen the responsibility of the province, Shandong Provincial Party Committee and provincial government further improve their political standing, integrate the work into the big chess game of the development of the party and the country, adhere to the concept of system, "six stability" and "six protection" work early, fast action, accurate direction, stable measures, effective.

In 2020, Shandong's agricultural production was generally stable, and its grain output reached a new record high. The total annual grain output was 54.468 million tons, an increase of 898000 tons over the 
previous year, an increase of $1.7 \%$. The total output has always been at the forefront of the country [9].

Shandong province implemented the employment priority policy, comprehensively strengthen measures to stabilize employment, reduce burdens, stabilize posts and expand employment, and do everything possible to enhance the stability of enterprises and their ability to create jobs. In 2020, 1227000 new urban jobs will be created in the province, exceeding the annual target; At the end of the year, the urban registered unemployment rate was $3.1 \%$, controlled at a low level of less than $4 \%$ [10].

To ensure stability and seek progress in stability. In 2020, after Shandong's economic growth reached - 5.8\% of GDP in the first quarter, it began to stabilize and recover in the second quarter [10]. The growth rate in the first three quarters turned from negative to positive, and the annual GDP growth rate reached $3.6 \%, 1.3$ percentage points higher than that in the whole country [10]. On the whole, the economic operation of the whole province shows a trend of comprehensive recovery and recovery, and the main indicators are better than the national average and expected. Zheng Shilin, an associate researcher at the Chinese Academy of Social Sciences, believes that these achievements in Shandong have indeed been hard won and have contributed to the country's overall situation.

Through the unprecedented baptism of 2020, the structure, quality, and efficiency of Shandong's economic development have been continuously improved. It can be said that it has not only kept the bottom line, stabilized the current situation but is also conducive to the longterm.

\section{RESULTS \& DISCUSSION}

In 2021, China needs to continue to adhere to the system concept, consolidate and expand the results of epidemic prevention and control and economic and social development, better coordinate development and security, do a solid job in the "six stability" work, and fully implement the "six guarantees" task.

Further, maintain economic operation within a reasonable range. Maintain the continuity, stability, and sustainability of macroeconomic policies, continue to implement proactive fiscal policies and prudent monetary policies and maintain the necessary support for economic recovery. A proactive fiscal policy must improve quality and efficiency, be more sustainable, and maintain a moderate spending intensity. A prudent monetary policy must be flexible, precise, reasonable, and appropriate, keep the money supply and the growth rate of social financing basically in line with the nominal economic growth rate and keep the macro leverage ratio basically stable. Strengthen economic monitoring, forecast, and early warning and policy pre- research reserves, and constantly improve the macro policy portfolio based on actual conditions. Strengthen anticipation management, do a good job in policy interpretation and publicity, respond to market concerns promptly, and stabilize the confidence of market entities.

At a greater distance, highlight the strategic guiding role of industrial policies. China will make overall plans to make up for short boards and forging long boards, implement key core technology research projects for weak links in the industry, and solve a number of "stuck neck" problems as soon as possible. Strengthen the basic status of competition policy and resolutely oppose monopoly and unfair competition. Accurately implement policies to promote industrial transformation and upgrading, implement industrial infrastructure reengineering projects, promote the integrated development of advanced manufacturing and modern service industries, promote the development of national strategic emerging industrial clusters, and promote the development of the digital economy.

Farther promote the formation of a strong domestic market. Combine the expansion of consumption with improving people's quality of life, tap new consumption potential, increase public consumption reasonably, promote the standardization and branding of services such as elderly care, childcare, and housekeeping, and fully tap the consumption potential of counties and townships. Optimize the direction of investment structure, enhance the potential for investment growth, give full play to the guiding and leveraging role of investment in the central budget in areas with strong spillovers and high social benefits, stimulate the vitality of investment in the whole society, promote the construction of major engineering projects during the 14th Five-Year Plan, and increase Invest in new infrastructure, promote the construction of key urban agglomerations, intercity railways in metropolitan areas, and municipal railways, and promote the transformation of old communities in cities and towns.

Further, do everything possible to stabilize and expand employment. Continue to stabilize and expand jobs, further stimulate the vitality of innovation and entrepreneurship, give play to the multiplier effect of entrepreneurship in driving employment, and support flexible employment through multiple channels. Strengthen precise assistance, carry out normalized monitoring and analysis of the employment of key groups such as college graduates and migrant workers, increase the implementation of work-for-relief, and create local and nearby jobs for migrant workers. Promote the co-construction and sharing of vocational skills training resources, provide workers with widecoverage, multi-level, lifelong vocational skills training, and improve their employment and entrepreneurship capabilities. 
Farther focus on stimulating market vitality. Promote the construction of a high-level socialist market economy system, implement an action plan for building a high-standard market system, deepen the reform of the market-oriented allocation of factors, and promote the high-quality development of the social credit system in accordance with the law. Deepen the reform of stateowned assets and state-owned enterprises, and accelerate the optimization and structural adjustment of the state-owned economy. Promote market-oriented reforms in the competitive sectors of industries such as energy, railways, telecommunications, and public utilities. Optimize the development environment of the private economy. Relax market access, promote fair competition, protect intellectual property rights, build a unified market, and create a market-oriented, legalized, and international business environment. Promote the high-quality development of the "Belt and Road" joint construction, and strengthen the capacity building of the China-Europe Express Rail Link. Actively participate in the global economic governance system reform and attach importance to using internationally accepted rules to maintain national security.

At a greater distance, it is expanding the new space for regional development. Continue to promote the decentralization and transfer of Beijing's non-capital functions, build the Xiongan New Area with high standards and high quality, accelerate the construction of intercity and municipal railways in the Beijing-TianjinHebei, Yangtze River Delta, Guangdong-Hong KongMacao Greater Bay Area, and replicate and promote the ecological and green integrated development of the Yangtze River Delta Demonstration zone system innovation experience, promote the ecological priority green development of the Yangtze River Economic Zone, and promote environmental protection and highquality development of the Yellow River Basin. China will steadily promote a new type of urbanization centered on people, improve the functional quality of large and medium-sized cities, solve the outstanding housing problems in large cities, and speed up county towns to make up for shortcomings.

Furthermore, China should continue to improve the quality of its ecological environment. Continue to fight the tough battle of pollution prevention and control, realize the synergistic effect of pollution reduction and carbon reduction, and prevent and resolve ecological security risks. Carry out work related to carbon peaking and carbon neutrality. Accelerate the construction of a national energy rights and carbon emission rights trading market. Strengthen and improve the dual control system of total energy consumption and intensity, and implement a comprehensive work plan for energy conservation and emission reduction during the 14th Five-Year Plan. Continue to promote the entire chain of plastic pollution control. Promote the green transformation of key industries and important fields.
Promote the development of renewable energy such as hydropower, wind power, photovoltaic power generation, and clean energy such as hydrogen energy, and increase the proportion of clean energy consumption.

Further, adhere to the bottom line of safety. Strengthen the responsibility system of the governor for food security, in-depth implementation of high-quality grain projects, strengthen the protection and utilization of germplasm resources, strengthen the construction of high-standard farmland, and improve the ability to guarantee the supply of grain and important agricultural and sideline products. Improve the level of safe, stable, and reliable energy supply, and further promote the construction of coal, electricity, oil and gas production, supply, storage, and marketing systems to ensure energy security. Prevent and resolve financial risks, use reform ideas and market-based legal methods to deal with the problem of corporate debt default, and promote financial innovation steadily and prudently.

Faced with all kinds of foreseeable and unforeseeable storms, storms, and turbulent waves, China needs to continue accelerating the construction of a new development pattern. And it will surely be able to overcome the epidemic's impact on the economy and strive to accelerate its economic growth to about $8 \%$ in 2021 [11], high in the front and low in the back. The three major demands are picking up faster. Consumption contributes more than $60 \%$ to economic growth. Consumption growth is expected to rebound to $13 \%$; investment growth will accelerate to $8 \%$. Manufacturing investment is expected to rebound to double-digit growth; export growth is accelerating [11]. At 6\%, the "filling up the deficiencies effect" has led to the unabated growth of exports [11]. The increase in CPI is controlled at around $1.5 \%$, and the level of inflation is relatively moderate [11]. PPI rose to $2 \%$, returning to a positive growth range after a lapse of two years [11]. The credit growth rate has dropped to $11 \%$, and tight credit will be a high probability event in the postepidemic period. The growth rate of M2 dropped to $9 \%$, and the monetary policy returned procyclically [11]. The fiscal deficit rate fell back to $3 \%$, and the fiscal policy returned to the trend, but the intensity remained unchanged [11].

Standing at the historical intersection of the "two centenary" goals, what new development China will pursue and how to achieve it is not only the Chinese people paying special attention to it but also the world's attention. In 2021, let us further deepen the "six stability and six guarantees", start the reform and opening up again, and see the beauty in the simple and pragmatic work, and thus make the world a better place. 


\section{CONCLUSION}

This article takes the late stage of the Chinese epidemic as the research background. It researches the recovery of China's economy in the post-epidemic period by China's six-stable and six-guarantee policy, especially the recovery of employment and investment. Through the literature review of the relationship between economy and employment and investment, this paper has conducted theoretical research and review and concluded that the relationship between economy, employment, and investment is mutually influencing and complementary, to further explore whether China's six stability and six guarantee policies mainly rely on stabilizing employment and investment To restore the economy. The article analyzes and compares the changes in China's GDP data before and after the epidemic and takes Shandong as an example to study the implementation of the six-stable and six-guarantee policy to solve the research problems raised in this article. Finally, the six-stable and six-guarantee policy focuses on stabilizing employment and investment in China. The economic recovery during the epidemic has made a great contribution. This also has significant enlightenment for China's future economic development. This article suggests that the policy can be updated, supplemented, and used to promote China's economic progress according to different developments and changes in different periods.

Studying the impact of the Six Stability and Six Guarantees on economic performance, especially employment and investment, will help to understand more clearly how China has emerged from the stagnant economic development during the epidemic and will have a negative impact on China and the world in fighting the epidemic on the economy. Has important research value and valuable experience. As the severity of the epidemic in each region of China is different, and the national conditions and control policies of each country in the world are different, China's six-stable and six-guarantee policy also has certain geographical restrictions. The situation has slightly changed, and if it is to be extended to all parts of the world, it needs to be changed according to local conditions.

In this paper, the research on data analysis is not indepth enough. It only uses some big superficial data as the analysis object without further digging. At the same time, in terms of empirical analysis, taking Shandong as an example also has certain limitations, and it exists. To sum up the problem, this is the shortcoming of this report.

\section{REFERENCES}

[1] Pang Yu \& Ma Yueyong. (2020). "Six Stability and Six Guarantees": Research on the Public Value of University Culture, Life and People. Heilongjiang
Higher Education Research (10),86-90. doi:10.19903/j.cnki.cn23-1074/g.2020.10.016.

[2] Pei Changhong. (2020). "Six Stability", "Six Guarantees" and the internal connection of highquality development. Research on financial issues (10),3-10. doi:10.19654/j.cnki.cjwtyj.2020.10.001.

[3] Gu Huaxiang. (2020). Research on the path of private enterprises focusing on "six guarantees and six stability" to promote high-quality development. Xinjiang Agricultural Reclamation Economy (07),1-11. doi:CNKI:SUN:NONG.0.2020-07-001.

[4] Zhong Changfu \& Wang Yuming. (2020). Some thoughts on innovative inclusive finance around "six stability" and "six guarantees". Heilongjiang Finance (07),57-59. doi:CNKI:SUN:HLJR.0.202007-025.

[5] Zhang Guoyun. "Six Stability and Six Protection" Further deepening, Reform and opening up again: China's economic operation 2020 Review 2021 Outlook. China Development Watch, 2021 (Z1) :62-64.

[6] Sina Finance. 2020 China Economic Statistics Communique released: A detailed analysis of the three carriages of economic growth, "Six stability", "six guarantees" and other data.[EB/OL].https://baijiahao.baidu.com/s?id=169 $2936912961186405 \& w f r=$ spider $\&$ for $=$ pc Visited 9 June 2021.

[7] South Fortune Net. . China's GDP in 2020 compared with 2019: ltis expected to exceed 100 tillion yuan.[EB/OL] http://www. southmoneyo com/caijing/cai jingyaowen/ 202101/8340462.html - Accessed 9 June 2021.

[8] [EB/OL].- China's economic development in 2019 review and 2020 China's economic development trend analysis [Figure].https://www. Chyxx. com/industry/202007/88 1083.html- acessed 9 June 2021

[9] Dazhong Newspaper Group. Shandong 2020 | ride the wind and waves, hand over the implementation of "six stability" "six guarantee" Shandong answer paper[EB/OL].https://baijiahaoEÈ. com/s? id $1689808993248021130 \quad \& w f r=$ spider $\&$ for $=p c$ Accessed 9 June 2021.

[10] Zhang Wei, Liu Yi. Shandong ssued a list of the third batch of policies to implement the "six stability" and "six guarantees" to promote highquality development. [EB/OL].http://sd.china.com.cn/a/2021/shouyejinri yaowen 0601/1027870.html accessed 9 June 2021 
[11] China Development Observation. Macro view | Deepening the "six stability and six guarantees", reform and opening up again-China's economic operation 2020 review and 2021 outlook [EB/OL]. https://m.thepaper.cn/baijiahao_11945448 June 9, 2021 access. 